\title{
The person-centred approach in maths skills development: examining a case of good practice
}

\section{Dr Russell Delderfield}

University of Bradford, UK

Helen McHattie

University of Bradford, UK

\section{Abstract}

The development of students' mathematics skills in higher education is often the topic of professional debate in learning development circles. Less prevalent are discussions taking place around the interpersonal dynamics that occur during one-to-one (tutorial) sessions. This case study explores these dynamics. It arose from the continuing professional development activities of an adviser (learning developer) at a UK university. As a result of recording one-to-one mathematics sessions it was found that the adviser was unconsciously competent and that, although she was adept at identifying her areas for development, she struggled to articulate the considerable strengths of her practice. We wanted to find a way of describing, analysing and evaluating her competence, and alighted upon the person-centred approach.

The aim of this paper, therefore, is to present the synthesis of maths skills practice with this approach in the hope of stimulating further research and professional conversation in the learning development community. The report offers novel idiographic findings through the application of person-centred theory to one practitioner's experience of delivering maths skills development. We conclude by suggesting that focusing on the relationship between adviser and student can help to create conditions conducive to successful one-toone education.

Keywords: learning developer; maths support; person-centred; maths advice; one-toone; academic skills; congruence; unconditional positive regard; empathy. 


\section{Introduction and background}

The development of students' mathematics skills in higher education is often the topic of professional debate in learning development circles (Fletcher, 2013; Perkin et al., 2012). Less prevalent are discussions taking place about one-to-one learning in maths support (frequently referred to as 'tutorials'). Rarer still is exploration of the relational aspects involved in one-to-one interactions. Wisker et al. (2007) suggest that there are fundamental skills and values when working one-to-one with students, such as observing, empathising, and being authentic and non-judgemental. However, these are not presented as qualities associated with the person-centred approach, which is a salient concept in this case study. Other works do conceptualise this link (Cooper and Reynolds, 2008; McGahey and Szumko, 2006) and even go as far as stipulating that person-centred values are key to learning development (Hartley et al., 2011). Focusing on maths practice, Croft et al. (2011) offer guidance to novice tutors. Whilst the advice provided is mainly about teaching skills in maths tuition, it also introduces concepts from counselling that have utility in a tutoring relationship. These are three 'conditions' necessary for successful one-to-one work, originally proposed by Rogers (1951/2003). Rogers argues that successful helping is achieved by putting the person at the heart of the process, hence his term 'person-centred practice' that is used in this case study.

Rogerian person-centeredness suggests that the strength and responsiveness of the helping relationship matters as much as (or more than) a set of prescribed interventions (Rogers, 1961/2004). Reflecting on people attending therapy, Rogers states that they are often nervous, see themselves as having a problem, and want to learn how to change (1951/2003). This echoes what students report about their maths competency. He suggests that in order for a session to be successful the practitioner should demonstrate congruence, acceptance (termed 'unconditional positive regard'), and empathy. These are presented as 'core conditions' for successful change and growth to be effected (Gidugu et al., 2015, p.450). In summarising these conditions, 'therapist' and 'client' are exchanged for 'adviser' and 'student'.

Congruence means that the adviser cannot be 'putting on an act' or pretending. The adviser has to be genuine so that the student feels secure and can trust the advice. To accompany congruence, an adviser can create an atmosphere of caring, irrespective of student ability. This is unconditional positive regard. It means the adviser treats students 
as worthy of their time and support, and does not issue subjective judgements about the person and their presenting maths needs (e.g. 'you should know this by now' is the antithesis to unconditional positive regard). Lastly, empathy is required. The adviser should be able to 'tune in' in order to see the student's experience from her/his point of view. This helps to glean why an individual student is struggling with a particular concept and allows the adviser to ascertain feelings that can inhibit understanding, such as frustration or disappointment (Blackie et al., 2010; Croft et al., 2011; Mearns et al., 2013).

The Croft et al. (2011) guidance about these three core conditions is the first of its kind to our knowledge, in that it creates an explicit link between person-centred values and maths support. However, the ideas remain unapplied and theoretical. This suggests that reporting this case study can offer original insight by applying the conditions to actual practice. The case arose from the continuing professional development activities of one adviser (learning developer), as part of her performance appraisal. We ( $\mathrm{H}$ and $\mathrm{R}$ ) wanted to find a way of describing, analysing and evaluating H's professional competencies. What emerged was the use of the aforementioned 'person-centredness'. This theory helped $\mathrm{H}$, an experienced practitioner, to process her practice. It facilitated reflection on the relational nature of one-to-one maths education. The purpose of this case study, therefore, is to present the synthesis of maths skills practice with the person-centred approach, in the hope of stimulating further research and conversation about one-to-one work in learning development.

\section{Case study}

In 2007, an enhanced focus on learning development at the University of Bradford led to the creation of the Academic Skills Advice service. This service, consisting of five staff, continually enhances its provision through an annual cycle of review and evaluation. An integral part of this is ensuring that individual advisers maintain their subject knowledge and continue to develop their practice. $\mathrm{H}$, one of two maths advisers, has been providing maths education, from basic to advanced level, for more than 15 years. She has taught maths using a variety of formats, from large classes with pre-planned learning activities, to responsive drop-in consultations. As one-to-one appointments are in-demand, these form a significant part of her current role. 
The focus here is on H's practice during these pre-arranged maths skills appointments. One-to-ones are an intensive form of interaction as there is no preparation for the adviser and they are largely student-led. The student decides on the topic(s) and brings the maths problems most pertinent to her/him. Students can be from any degree discipline and range from those struggling with basic maths to those who want to maximise their chances of achieving $1^{\text {st }}$ class or distinction marks.

Students return to see $\mathrm{H}$ and also recommend her to other learners. However, $\mathrm{H}$ had not rigorously analysed why the feedback was consistently positive. It is suggested here that years of practice had resulted in unconscious competence (Cannon et al., 2010) in one-toone work. It seems that $\mathrm{H}$ creates a positive and stimulating environment, without conscious attention to the relationship fostered between learner and adviser, that allows students to tackle their confidence and skills issues in maths without feeling overwhelmed or demoralised.

Peer-supported Review of Practice (PSRP) is one aspect of the University of Bradford's commitment to continuous teaching quality development. It involves colleagues observing one another's practice to provide constructive feedback and identify future areas for development. $\mathrm{H}$ and $\mathrm{R}$ (another adviser with a different specialism) were partnered as part of PSRP. In order to explore and evaluate H's practice, a minimally-invasive strategy was chosen whereby $\mathrm{H}$ video-recorded sessions in the autumn term. The recorded material was reviewed in the winter.

Recorded sessions involved four students: two one-to-ones and one pair. All students gave verbal consent for recording. $\mathrm{H}$ and $\mathrm{R}$ reviewed the recordings together, multiple times, whilst taking running notes of evaluative observations. It was decided to review all recordings to ensure a full and realistic example of day-to-day maths support. A thorough qualitative analysis was then carried out by the reviewer and shared with the reviewee to scrutinise. Once the reviewee had had time to reflect on the analysis, both met to agree final areas for development and to discuss professional practice. This is referred to as the 'debrief'. What follows is a summarised version of reviewer observations:

- A calm and purposeful working atmosphere was fostered;

- Open questioning and redirection were used well; 
- Differentiated methods of correction, including corrective questioning, were exemplary;

- Correction was 'honest' but presented as neutrally as possible, without use of judgemental language or negative non-verbal cues;

- Positive reinforcement was employed to draw attention to successes;

- Rapport and motivation were created through non-verbal cues (mirroring of individual's posture when listening, for depth);

- Silence was 'held' and utilised for deeper learning.

In the debrief $\mathrm{H}$ explained these behaviours and skills as emanating from three elements of an ethos she espoused. Firstly, she does not want to perpetuate people feeling 'bad' about needing support with maths. Secondly, she believes that everyone can excel with appropriate support. Finally, she knows that the students have a better experience if they are made to feel like mistakes are part of the process, rather than insurmountable obstacles. Whilst this was respected as H's view, it seemed insufficient to account for the extensive learning developer work that was evident on-screen. The reviewer suggested that using person-centred theory could help $\mathrm{H}$ to articulate what transpires during interactions and, therefore, why students repeatedly report positive experiences. The following discussion captures the application of the core conditions to H's practice.

\section{Discussion}

\section{Congruence}

In the case of a maths skills appointment the student needs to feel safe enough to admit their problems and not be made to feel 'silly' about asking what can feel like 'obvious' questions. Students often imagine that someone more experienced with maths does not commit errors, so it is important to model for them that it is 'OK' to make mistakes. This was evident in H's practice when, during an individual one-to-one, she was observed selfcorrecting a method she was teaching. She verbally acknowledged 'that doesn't work, does it? l've made a mistake somewhere along the line'. This is congruence at work. Rather than bluffing through an error, or simply correcting without acknowledgement, she showed the student how to deal with the mistake. This had the added benefit that she then modelled how to backtrack in order to problem solve step by step, talking through her real- 
time thought process. As $\mathrm{H}$ reflected, this helped the student to trust her, as well as acquiring strategies for resolving mistakes.

\section{Unconditional positive regard}

For students to engage productively, they need to feel that advisers care about their learning. $\mathrm{H}$ showed that she accepted a variety of obstacles and emotional responses from the students, without judgement. During debrief $\mathrm{H}$ commented: 'We have to accept: their mistakes; their not understanding; that they don't like maths; that they can't understand their lectures'. These responses have to be processed without affecting an adviser's regard for the learner. $\mathrm{R}$ observed that, in conjunction with honesty when she corrected poor or incorrect maths practice, $\mathrm{H}$ used positive reinforcement liberally when students had breakthroughs in their understanding or achieved the desired answer. It was a recurring theme throughout recordings that students were made to feel welcome and comfortable instantly, and that they felt 'OK' to express misgivings and negativity about their previous experiences with maths.

\section{Empathy}

This was a significant point of reflection for $\mathrm{H}$. She expressed how, having taught maths for years, it can be easy to forget her early experiences as a maths learner. She suggested that the more time that passes, the more difficult it can be to remember how it felt to learn the subject; how many different concepts there seemed to be, and how difficult it was to put them all together and remember what to do and when. She said it can be too easy to indulge in negative regard for the learner, thinking: 'this is so easy - what is the problem? Why can't you do this?'. Later she reflected: 'We have to get our thinking out of that world and into the world of the student who is seeing this for the first time'. The reviewer felt this was evident in the recordings. H subconsciously mirrored her students' body language, which is a useful way to show empathy (Knox, 2008). She paraphrased phrases and statements they expressed to show she was following them closely and understood their concerns and frustration (Sanders, 2011). At one point in a session, whilst modelling some maths, she clearly sensed the learner's unspoken confusion, checked-in with them, then, without prompting, formulated another way to explain the process. 
A final example of 'tuning in' to the learner emerges from H's adept use of silence. There were several instances in recordings where $\mathrm{H}$ said nothing, maintained open body posture and regular, neutral eye-contact. This time appeared to be well-used by the students. One decided to take more paper and try something out before responding further. Another clearly sat thinking and then asked a question, which $\mathrm{H}$ was able to use as a teaching point. Using silence in this way requires empathy, as otherwise it can be misjudged and illtimed, coming at the wrong point during the interaction and causing the student to feel misunderstood, or awkward.

\section{Implications}

Examining the observations made about H's practices using the core conditions demonstrates that 'just being good at high-level maths' is insufficient when developing learners during intensive one-to-one work. Not only will an accomplished adviser be able to establish rapport but they will be able to maintain it through challenging situations, such as learners experiencing frustration and failure. $\mathrm{H}$ uses the relationship she builds with the learner as much as she uses maths teaching strategies. Her empathic response to students' verbal and non-verbal cues, as well as her consistent positive regard for the learner, combine to create an environment in which mistakes are acceptable and can be exploited for learning. Similar to other professions, learning development involves the practitioner's values and qualities, not just an extensive knowledge of the skills that they teach.

\section{Concluding reflections}

This study offers a novel starting point for conceptualising the importance of 'relationship' in maths skills work. It has explored behaviours and qualities, that an experienced adviser might take for granted, through the lens of Rogerian core conditions using one learning developer's practice. Taking its inspiration from the world of therapy, the paper has suggested that focusing on the relationship between adviser and student can add to existing learning development knowledge by proposing conditions for successful one-toone practice with students. 
Limitations are part of any synthesis of theory and practice, and this study is no exception. $\mathrm{H}$ recorded three out of hundreds of sessions. Recording was done by convenience and where students verbally assented. During preparation for this paper, both reviewer and reviewee identified that the experience of being recorded could lead to changes in adviser practice, e.g. nervousness. Similarly, even though students were informed they were not under scrutiny, it cannot be guaranteed that they did not behave differently during the interaction. It is also important to note that this represents one case study of a single practitioner; therefore, there is no generalisability to offer. Although, it is hoped that other learning developers may reflect on H's experience and evaluate how it echoes or differs from their own.

Future research could involve qualitative analysis of observed practitioner values across a variety of settings. Additionally, alongside focusing on the practitioner, the student voice could be captured. This may offer valuable data about learners' expectations and experiences of receiving one-to-one maths support.

By way of concluding remarks, this review led to individual insight for the experienced adviser: after all, there is discussion about the value of becoming unconsciously competent in one's craft but little about what follows beyond this. Engaging in this study also invigorated professional discussions within our service about the nature of the extensive one-to-one work we do and why we have our ethos. Keeping these discussions fresh and critical is not only beneficial to us, but to our learners, which is why we are here.

\section{References}

Blackie, M.A., Case, J.M. and Jawitz, J. (2010) 'Student-centredness: the link between transforming students and transforming ourselves', Teaching in Higher Education, 15(6), pp. 637-646 [Online]. Available at:

http://www.tandfonline.com/doi/abs/10.1080/13562517.2010.491910 (Accessed: 12 June 2017). 
Cannon, H.M., Feinstein, A.H. and Friesen, D.P. (2010) 'Managing complexity: applying the conscious-competence model to experiential learning', Developments in Business Simulation and Experiential Learning, 37, pp. 172-182 [Online]. Available at: https://journals.tdl.org/absel/index.php/absel/article/view/306 (Accessed: 12 June 2017).

Cooper, J. and Reynolds, A. (2008) The one to one toolkit: tips and strategies for advisers, coaches and mentors. $2^{\text {nd }}$ edn. London: CareerTrain.

Croft, A.C., Gillard, J.W., Grove, M.J., Kyle, J., Owen, A., Samuels, P.C. and Wilson, R.H. (2011) Tutoring in a mathematics support centre: a guide for postgraduate students. Edgbaston: The National HE Stem Programme. Available at: http://www.mathcentre.ac.uk/resources/uploaded/46836-tutoring-in-msc-web.pdf (Accessed: 9 March 2017).

Fletcher, L. (2013) The mathematics support community of practice. Edgbaston: The National HE Stem Programme. Available at: http://www.sigma-network.ac.uk/wpcontent/uploads/2012/11/sigma-final-report.pdf (Accessed: 23 June 2017).

Gidugu, V., Rogers, E.S., Harrington, S., Maru, M., Johnson, G., Cohee, J. and Hinkel, J. (2015) 'Individual peer support: a qualitative study of mechanisms of its effectiveness', Community Mental Health Journal, 51(4), pp. 445-452 [Online]. Available at: https://www.ncbi.nlm.nih.gov/pubmed/25535049 (Accessed: 8 July 2017).

Hartley, P., Hilsdon, J., Keenan, C., Sinfield, S. and Verity, M. (eds.) (2011) Learning Development in Higher Education. Basingstoke: Palgrave MacMillan.

Knox, R. (2008) 'Clients' experiences of relational depth in person-centred counselling', Counselling and Psychotherapy Research, 8(3), pp. 182-188 [Online]. Available at: http://www.tandfonline.com/doi/abs/10.1080/14733140802035005 (Accessed: 12 June 2017). 
McGahey, P. and Szumko, J. (2006) 'Relationship at the heart of helping', BRAIN.HE 2006: BRAINHE one day conference. De Montford University, Leicester 15 September. Available at:

http://www.brainhe.com/resources/2006BRAINHEconference.html (Accessed: 14 July 2017).

Mearns, D., Thorne, B. and McLeod, J. (2013) Person-centred counselling in action. London: Sage.

Perkin, G., Lawson, D. and Croft, T. (2012) Mathematics learning support in higher education: the extent of current provision in 2012. Edgbaston: The National HE Stem Programme. Available at:

http://www.mathcentre.ac.uk/resources/uploaded/52789-mls-in-uk.pdf (Accessed: 9 March 2017).

Rogers, C.R. (1951/2003) Client-centred therapy. London: Constable and Robinson Ltd.

Rogers, C.R. (1961/2004) On becoming a person: a therapist's view of psychotherapy. London: Constable and Robinson Ltd.

Sanders, P. (2011) First steps in counselling: a student's companion for introductory courses. $4^{\text {th }}$ edn. Ross-on-Wye: PCCS Books.

Wisker, G., Exley, K., Antoniou, M. and Ridley, P. (2007) Working one-to-one with students: supervising, coaching, mentoring, and personal tutoring. Abingdon: Routledge.

\section{Author details}

Dr Russell Delderfield is Senior Academic Skills Adviser (Postgraduate Research Development), Academic Skills Advice, University of Bradford.

Helen McHattie is Academic Skills Adviser (Mathematics), Academic Skills Advice, University of Bradford. 